\title{
Preparing public participation at the catchment level : Comparison of three methodologies applied to the Hérault river basin
}

\author{
S. Loubier ${ }^{\star}$, J.-D. Rinaudo*, P. Garin ${ }^{\star \star}$, A. Boutet ${ }^{\star \star \star}$ \\ *BRGM, 1039 rue de Pinville, 34000 Montpellier, France; e-mail: s.loubier@ brgm.fr \\ ** Cemagref, BP 361 rue JF Breton, BP 5095, 34196 Montpellier cedex 5 \\ *** ENST, technopole Brest Iroise, CS 83818, 29238 Brest cedex 3.
}

\begin{abstract}
Public participation in water resources management has increasingly been recommended to increase the effectiveness and the acceptability of proposed water management projects and plans. Different levels of public participation are possible depending on the governance context. This paper reports on the practical implementation of three different methodologies in the Hérault river catchment (France). The analysis of public view points, carried out using a quantitative opinion survey and focus groups, reveals important information needs which have to be fulfilled for any further consultation to be efficient. A complementary analysis of stakeholders' opinions, carried out through semistructured interviews also highlights the need to construct a common knowledge base between stakeholders, expert and scientists. This is seen as a prerequisite to implementing more elaborated forms of participation.
\end{abstract}

Keywords Public Participation; Water Management; France; Qualitative Analysis

\section{Introduction}

Since Rio de Janeiro conference (1992), the need to involve stakeholders in water management and planning, has been repeatedly advocated by the international community in conference and intergovernmental summit statements (Dublin 1992, La Hague 2000, Bonn 2001, et Kyoto 2003). More recently, the European Union has turned that principle into practice with the adoption of the Water Framework Directive (noted WFD below). In its article 14, this Directive imposes that stakeholders be actively involved in the preparation of the water management plans and that the public at large be consulted during the planning process. ${ }^{1}$

According to Craps et al. (2003), the foundation of the public participation principle in water management planning are found in the limits of the two main governance models: the centralized top-down model (Ingles et al., 1999) and the liberal model which rely on market forces to integrate social changes in minimising government interventions. The participative model provides an answer to growing expectation of the public, reinforces the legitimacy of decision-making and increases the effectiveness of measures chosen and implemented, particularly in southern countries characterised by a certain weakness of power regulation (Deepa, 1993). But public participation is not an end in itself. What matters above all, is the

\footnotetext{
${ }^{1}$ As defined in Aarhus convention.
} 
social learning process initiated by participation, i.e. the progressive increase of the capacities of a complex system - composed of people belonging to different social entities sometime in conflict - to perform common tasks on a given territory. Social learning is then both a process and a result (Craps, 2003).

Because of lack of time, means and know-how of the relevant authorities, the practical implementation of these governance changes remain a real challenge. Very often, relevant authorities tend to prefer mobilising experts and scientific knowledge for supporting their decisions than associating the public to the debate. In France, public consultation only takes place at a late stage of the decision making process, the population being only allowed to comment in a written form on the results of the decisions prepared by experts. Public comments are rarely taken into account and consequently, consultation does not prevent the emergence of conflicts, with organised opposition groups blocking the implementation of the approved measures. The limits of this weak form of public participation have been highlighted during the last two decades in Northern European countries where public authorities actively try to obtain population support. In the Netherlands for instance, public is associated to the planning process from its beginning, i.e. before the alternative options are chosen (De Vries, 1997). Public participation, however, is highly dependent on population cultural, historical and political background and it is not obvious that the Dutch model for instance can be relevant and successfully implemented in France.

This paper presents a first attempt to investigate this issue in the Frnch context. The main objective of the paper is to illustrate, through a real case study, the potential benefits of different forms of public and stakeholders consultation at an early stage of the decision making process. The research has been conducted by BRGM and Cemagref in a Southern France catchment, where a participative planning process has been initiated by local government. It aims at producing recommendations and guidelines for policy makers involved in the implementation of article 14 of the WFD. More specifically, it aims at illustrating how different operational methods can be used to prepare participation of the civil society, with a focus on the three following aspects :

- The identification of public information needs : because water management is a complex and multi-facet issue, involving different types of knowledge, and referring to complex notions such as risks, amenities, uncertainties, resilience, etc., a significant knowledge gap may exist between expert and laymen (Rinaudo and Garin, forthcoming; Theys, 2003). Measuring this knowledge gap, trying to reduce it through appropriate information measures, and developing a common knowledge base, clearly represent necessary conditions for a real and high quality debate with the civil society.

- The identification of stakeholders to be associated to the debate : this problem, which is common to all forms of participatory democracy, is that of the selection of legitimate spokespersons to represent the different interests at stake. There is no standard procedure to do so, and it belongs to the relevant authority to carry out this choice which significantly determine the outcome of the debate.

- The characterisation of public perception of the issues at stake at the beginning of the participation process. The definition of such a reference point can be used (i) as a bench mark to assess the effects of the participative process on the perception of the public and (ii) the extent to which the decision makers have taken into account the expectation of the civil society in the decision process. This is crucial to ensure long term and sustainable public participation : the public has to be convinced that its contribution had a real impact on the decision makers. 
The paper is organised as follows. The next section briefly describes the case study. It is followed by a review of existing methodologies to analyse public perception. The main results are presented in the third section and discussed in a concluding section.

\section{Presentation of the study context: The Hérault river basin}

The Hérault catchment is a small Mediterranean coastal river basin which takes its spring in the Cévènnes mountains at 1280 meters altitude and 70 kilometres North of the coast. Despite its relatively small size (2500 square kilometres, 152000 inhabitants), the catchment is very heterogeneous in term of geology, hydro-geology and land and resource uses. The Mediterranean climate (dry summers and wet autumns) coupled with specific socioeconomic characteristics in permanent mutation, frequently generates water quality and quantity related tensions. From a socio-economic point of view, the catchment can be divided into four major areas:

- The most up-stream region is mountainous, sparsely inhabited and the main activities are a declining textile industry, rural tourism and vegetable farming activities. River quality problems are the main source of tension, with few additional conflicts related to the use of the river space between fishermen, canoeing and riparian land owners.

- South of this area lies a large karst plateau, characterised by a low population density and an economy driven by tourism and extensive agriculture; this area has significant un-exploited groundwater resources which could be tapped in the future by neighbouring cities - a perspective perceived as a threat by locals inhabitants.

- Population density is much higher in the middle Hérault valley which is connected by a motorway to the two major towns of Montpellier and Béziers. There, the major issue of concern of local actors is the sharing of river flow between irrigated agriculture, the drinking water sector, leisure activities and hydropower generation.

- Finally, the coastal area, where more than half of the permanent population of the catchment lives, is mainly oriented towards tourism. Issues of concerns are related to drinking water (satisfaction of peak seasonal demand) and flood risk.

To address these issues of concern, the local authorities have proposed in the late 1990's to develop an integrated Water Management Plan (WMP) using the participative approach defined by the French Water Act of 1992. This WMP is developed by an Executive Board, comprising representative of Government Agencies (one third of the seats), elected politicians such as mayors (one third), and spokespersons designated as legitimate representatives of the various interests at stake. Public participation is supervised by the Government which defines the boundaries of the area concerned by the WMP as well as the composition of the Board. In most cases, Board members are chosen among organised groups of stakeholders having a professional relation to water resources (e.g. farm or industrial unions and lobbies) and associations (fishing, water related sports, riparian land owners, environment protection associations, etc). The number of representatives and stakeholders can be extended if the Board decides to establish ad hoc working groups to debate on site specific problems (geographic working groups) or sector-specific problems (agriculture, industry, groundwater, etc.) in which a larger number of participants can be invited.

Preliminary studies commissioned by a territorial body in the late 1990's lead to the conclusion that water management was not a real issue of conflict in the catchment. They however pointed out that integrated water management was likely to become a much more complex and conflicting issue in a close future, due to rapid population growth. This 
perspective has motivated the decision to initiate a participatory planning process, in view of creating a social learning process that could facilitate future collective choices. This initiative was however not accompanied by actions aiming at involving or consulting the public at large. This context of emerging participation was therefore judged appropriate to test methodologies to analyse the perceptions of the concerned population.

\section{Methodologies to analyse public perception}

\section{A typology of consultation methods}

Among the different forms of public participation to decision making, consultation is characterised by the lowest level of public involvement (Mostert, 2003). It consists in collecting the opinions of a group of persons on a specific issue. Mostert distinguishes ten consultation methods which he classifies into five categories:

The three first categories consist of methods which aim at collecting the view points of large groups of individuals (several hundreds) :

1. Face to face, phone and mail surveys which provide a quantitative assessment of the opinion of the public, using the results found with a statistically representative sample of a population; this does not allow however to assess the willingness of the population to participate to the debate.

2. Consultative referendums which aim at assessing the level of acceptance (or refusal) of a specific proposal (project, policy) by a well defined population - but with no possibility to understand the motivations underlying the opinion expressed.

3. Public enquiry and internet forum discussions which allows the expression of motivated opinions of a large number of individuals; the view points collected are however not representative of the vision of the concerned population, this type of consultation being based on voluntary acts.

The fourth and fifth categories consists of methods targeting small groups of individuals and aiming at providing an in depth qualitative description of opinions and of the underlying arguments :

4. Semi-structured interviews are used to characterise the opinions and perception of a small and statistically unrepresentative sample of individuals. This approach aims at characterising the diversity of the opinions of the population concerned by a project or policy (stakeholder analysis, developed by Grimble and Wellard, 1997) - with no possibility to extrapolate the findings to the entire population. Defining who is the concerned population and identifying the stakeholders to be interviewed is a key step of the process.

5. Games and Focus Groups consist in having a limited group of individuals present and debate their opinions and perceptions. Such methods do not aim at reaching a consensus on a given issue but to understand participants' feelings, argument, and the underlying values and beliefs (Krueger and Casey, 2000). The quality of the information obtained depends on the level of interaction between participants. Depending on the study objectives, groups can be composed by stakeholders or citizens.

In the following paragraphs, we present how we have implemented three of these methods in the Hérault catchment: semi structured interviews with stakeholders; a population survey; and focus groups with citizens.

The three methodologies tested in the Hérault case study 
Semi structured interviews were carried out at the beginning of the research (2001) to identify major stakes and issues of conflict in the catchment. The methodology used is largely based on the stakeholder analysis principles as defined by Grimble and Wellard (1997) for analysing public policy acceptability. Using a semi-structured questionnaires, we interviewed 71 representatives of stakeholders (agriculture, industry, tourism, drinkable water and various NGO), all being potential members of the WMP executive board (which was not yet established at that time). The objective was to describe the opinion and perception of stakeholders before the debate was initiated. The interviews were guided by a semi-open questionnaire designed to (i) evaluate the respondents' level of knowledge and information concerning water resources, (ii) identify water-management problems they are concerned about, and (iii) inventory and characterise current or potential water-use conflicts and their areas of influence. The perceptions and visions of the interviewees were then compared to the conclusion of the preliminary expert studies (Garin et al., 2002, Rinaudo and Garin, forthcoming).

A quantitative opinion survey was then carried out (2003) with a sample of 400 households representative of the population in terms of gender, age, professional occupation, type of housing, tenancy (renter /owner), type of area (rural / urban) and location within the catchment. Interviews were carried out face to face at the respondents' home, using a structured questionnaire comprising more than 80 questions. ${ }^{2}$ Results where analysed using descriptive statistics, multiple correspondence analysis and agglomerative hierarchical clustering to build a typology of attitudes, opinions and perceptions (Loubier and Rinaudo, 2004).

Focus groups were organised in parallel with the survey, bringing together some of the citizen met during the survey and who had accepted to participate to discussion groups on water issues. Three such groups were organised at the end of 2003 and beginning of 2004 with the following objectives : (i) collect information not revealed during the survey, (ii) refine the survey results with an in depth qualitative analysis of the argument used to justify the positions defended (not possible with the survey) and (iii) test the feasibility of this method as an operational tool for implementing article 14 of the WFD. The groups were organised in a neutral place (school) during evenings. They brought together 3,5 and 6 citizens who debated between one and a half to two hours. One researcher from the team played the role of the moderator and the cessions were video recorded to allow a detailed analysis by the other members of the team. The moderator tried to supply as little information as possible in order to avoid influencing the discussion - but he had to answer some of the questions raised to prevent any feeling of frustration among participants. The discussion was oriented by discussion guidelines containing a list of topics to be discussed by the group: perception of water quality in the environment; discussion of water consumption behaviours; and expectations related to participation. The moderator initiated the debate with introducing the different topic with a precise question. Its role was then limited to boost the debate, balance speaking time and reorient the discussion when needed.

\section{Results}

\section{Semi-structured interviews and stakeholder analysis}

\footnotetext{
${ }^{2}$ As part of the EU funded research project AQUADAPT, the same survey was simultanously undertaken in a Slovenian, a Spanish and an English catchment using a set of 60 common questions (see ww.aquadapt.net).
} 
The information collected through interviews was scrutinised from two angles: we first analysed the differences of view points and knowledge between stakeholders; then, we focussed on the analysis of existing conflicts over water use, that we considered to be the central issue to be addressed in the water planning process in the Hérault valley.

We found that certain stakeholders had serious knowledge deficiencies concerning water resources and uses in the catchment. Actors from the agricultural sector and Government services generally have a comprehensive and multi-dimention vision of the hydro-system functioning. Others, in particular within the drinking water sector, have a very narrow and local vision of water resources, and their discourse even sometimes reveal severe misconception on water resources (Garin et alii, 2002). In particular, the nature of the different hydrologic compartments and their interaction are frequently not understood. This clearly highlights any debate on water management options should absolutely be preceded by programmes of information and training. Moreover, these programmes should be differentiated and adapted to the needs of the different categories of stakeholders.

The interviews were also useful to compare the main concerns of actors with the key management issues identified by experts in the preliminary studies of the WMP (CG34 and CG30, 1998). Stakeholders are not always aware or underestimate the significance of certain problematic issues (for instance erosion and solid transport in the river). Symmetrically, some of the problems quoted by stakeholders are not perceived as such by experts : for instance, while experts consider that water management is not a source of tension in the catchment, stakeholders are deeply concerned by existing conflicts and wish that a stakeholder platform be established to solve the problems collectively. The interviews also highlighted that stakeholders rarely share the same concerns, which results in difficulties for all parties to identify the real stakes of the debate and the negotiation that will accompany the planning process (Garin et alii, 2002).

A number of conflicts were also quoted by stakeholders interviewed. The major one is linked to a large gravity canal irrigation system which withdraw a very significant discharge in the river, sometimes hardly leaving a few hundred litters per second in the river during low water flow periods. This creates tensions between farmers and recreational uses (fishing, bathing, canoeing) and environment associations. The defenders of the canal point out that irrigation has significant positive externalities such as the recharge of the aquifer, a positive impact of the landscape, and a reduction of the domestic water demand in the municipalities it crosses (households can use this water to irrigate their gardens). However, this argument is largely contested by the opposing party. Due to the lack of any scientific study of the aforementioned externalities, a situation of blockage of the debate appears, preventing the formation of a consensus on this issue. This example illustrates how a stakeholder analysis, conducted before the beginning of the planning process, can help identifying the scientific and technical information needed by stakeholders to settle certain conflicting issues or disputes.

Semi-structured interviews can also help identifying latent conflicts, perceived as such by some stakeholders but which do not yet figure on the political agenda of policy makers. An illustration in the Hérault catchment is provided by a drinking water project, which would consist in exploiting a remote karst aquifer to supply the city of Montpellier, several dozen of kilometres outside the catchment. The interviews showed that this project is likely to crystallise future resentment between the stakeholders concerned by the development of the main city of Montpellier and those of the peripheral rural areas. The latter considering they do not derive sufficient benefits from the rapid economic and growth of Montpellier; they consider that "their" groundwater resources could be used by themselves in the future and shouldn't be exported - unless a compensation is paid. Stakeholders consulted proposed 
several alternatives to this project - another benefit of non expert input in the preparation of the debate. This example also illustrates that certain stakeholders located outside the catchment should be associated to the identification of the water management issues, in order to reduce the risk of dispute during the consultation stage when water management plan will be submit to the public for comment.

\section{Quantitative survey and focus groups}

Out of the 80 questions of the questionnaire presented above, we only discuss, in the paragraph that follows, those aiming the assessing the level of (water related) knowledge of the population and the perception of public participation.

The survey shows that the inhabitants of the catchment are not really concerned by environmental and water issues : they are quoted in respectively fourth and fifth position in a proposed list of seven issues of concern (which includes employment, security, international politics, etc). Coherently, the percentage of the population asserting that water quality in the environment has deteriorated in the recent past $(32 \%)$ is twice smaller than reported in national surveys. More surprisingly, more than $40 \%$ declare that it is urgent to tackle water related problems in the area where they live. But in spite of the perception of this relative emergency, only one person in four would like to be involved in discussions and debates about present and future water resource management. People who refuse to participate explain that their opinion would not influence the final decision, which can be explained by several assumptions: (i) inhabitants do not trust their elected representatives for taking into account their points of views, (ii) they do not feel concerned by water management and would not invest time in discussion on that topic and/or (iii) they are relatively confident in the existing management organisations ( 7 in 10 believe that such organisations exist at all geographic level). ${ }^{3}$ People who would like to be involved (25\% of the respondents) have a preference for participation at a local level (14\% would like to be involved at national level, $37 \%$ at regional level, $51 \%$ at departmental level and $88 \%$ at the local one). This group is composed of slightly younger people, having a higher level of education than the average of the sample. They envisage their participation under various forms: a contribution to public debates or consultation, direct participation to the decision making process (i.e. without any representatives of their interests). This stated position calls challenges the legitimacy of NGOs, which claim being representatives of citizens and which are invited as such to actively participate (in the sense of the WFD) in dialogues organised by the authorities.

However, the actual willingness to participate appeared to be much lower than declared when we invited the respondents to participate to focus groups. Out of the 100 persons supporting the principle of public participation, more 44 refused to participate to focus groups we offered to organise in their region. A few weeks after the survey, 44 of these 66 individuals were contacted but only 25 confirmed their initial wish to participate at an agreed place and date. Ultimately, only 14 of them actually came to the meetings ${ }^{4}$. One possible assumption to explain this gap between declared intentions and actual behaviour is that the organisation of people's priorities into a hierarchy has been done at the expense of the initial participation wish, even if water management related issues had been identified as prime importance during the survey.

\footnotetext{
${ }^{3}$ People thinking that such organisations exist declare that they are established at the European level $(41 \%)$, at the national level $(67 \%)$, at the regional or departmental level $(73 \%)$ and at the local level (municipality or group of municipalities : $62 \%$ ).

${ }^{4}$ Extrapolating, this represent $5 \%$ of the initial sample.
} 
Despite this low rate of participation, the three focus group cessions have highlighted several key elements enabling a better understanding of citizens' behaviours and representations. Concerning the motives for participation, participants seem to be in search of scientific information : they considered the moderator as an expert which they question and take as a witness. ${ }^{5}$ As noted earlier with stakeholders, citizens also have a very limited knowledge of the components of the hydro-system, its geographic limits and its functioning. Their perception of water related issues and options is strongly determined by their daily experiences : most of them spontaneously talk about drinking water quality but the moderator had to insist to have a discussion on other issues such as water quality within the environment. More generally, the lack of knowledge and misconceptions identified during the survey are confirmed. But these focus groups also highlight the capacity of some persons - a priori neither experts nor stakeholders - to defend and argue on sometimes diverging opinions, especially concerning the quality of water. These lessons reinforce the idea that providing information is a prerequisite to consultation and a fortiori other more ambitious forms of participation.

\section{Discussion : the role of experts and scientists}

The three consultation methodologies tested in the Hérault catchment provide complementary insights into public perceptions. Focus groups are useful to understand the argument of the public when talking of water related issues and options as well as the factors that can influence water use behaviours. The survey gives complementary qualitative data on these behaviours. The combined implementation of these two approaches can be used to characterise the level and the quality of public knowledge and to assess the type and the relevance of the contribution that can be expected if a consultation is carried out. Moreover, focus groups help understanding how individuals may react and express opinions in a public arena which can provide useful information for preparing more ambitious forms of participation (public debates or forums, etc).

Not surprisingly, the Hérault case study confirms that the public at large is poorly informed on water issues and related stakes. It would therefore be illusive to expect any significant mobilisation and relevant contribution of the public if consulted on a WMP, without any specific awareness and information campaigns. For experts and scientists, the challenge is to offer their knowledge but also share their uncertainties with a large population, using a language understandable by laymen. A significant communication effort should made to ensure that (i) public opinion, perception and judgement are based on reliable information and (ii) that consultation can efficiently contribute to the design of a WMP understood and accepted by the largest possible number. This fact has already been pointed out by several scholars and experts (see for instance Mostert 2003)

The case study also highlights the benefits of semi structured interviews and stakeholder analysis in identifying the issues sources of tension (actual or latent) as well as the deficiencies and/or asymmetries of information which can prevent their resolution. This approach is also helpful to identify the appropriate geographic area which has to be considered when designing the WMP. Because political and economic boundaries rarely follow river catchment, it is important to identify all stakeholders likely to be concerned by the WMP, especially those located outside the catchment who would not be spontaneously associated to the talks.

\footnotetext{
${ }^{5}$ To prevent this, (Blach and Mertens, 1999) recomend to take a moderator that do not belong to the research team to improve the quiality of the collected information.
} 
Last, the three early consultations carried out in the Hérault case study provide an initial picture of public perceptions. This picture can be used as a reference point to monitor the evolution of public perceptions and expectations during the consultation process which will last several years and will be repeated every six years when updating the WMP.

\section{Acknowledgement}

The research presented in this paper is based on the results of two EU funded research projects AQUADAPT (EVK1-CT-2001-00104) and GOUVERNe (EVK1-CT-1999-00043). The authors also acknowledge the financial support of the French National Research Center (CNRS).

\section{References}

1. Blach, G.I., Mertens, D.M., 1999. Focus Group Design and Group Dynamics: lessons from deaf and hard of earing participants. American Journal of Evaluation 20 (2):265-277.

2. Conseil Général de l'Héraut et Conseil Général du Gard, 1998. Schéma d'aménagement et de gestion des eaux : dossiers de travail pour la commission locale de l'eau.

3. Craps, M., 2003. Social learning in basin management. HarmoniCOP Report: December 2003: 70. Available at: www.harmonicop.info

4. Craps, M., Van Rossen, E., Prins, S., Tailleu, T., Bouwen, R., Dewulf, A., 2003. Social learning and water management: Lessons from a case study on the Dijle catchment. in Proceedings of the Connections Conference on "Active Citizenship and Multiple Identities", Leuven, September 2003: 418-429.

5. Deepa, N., 1993. Participatory evaluation: tools for managing change in water and sanitation. World Bank, Washington:122.

6. De Vries, M.S., 1997. La gestion de la participation publique dans le processus politique: l'exemple des Pays-Bas. Revue Internationale des Sciences Administratives, 1997/2: 161182.

7. Garin, P., Rinaudo, J.-D., Ruhlmann, J., 2002. Linking expert evaluation with public consultation to design water policy at the watersheed level. Water Science \& Technology 46 (6-7):263-271.

8. Grimble, R., Wellard, K., 1997. Stakeholder methodologies in natural resource management: a review of principles, contexts, experiences and opportunities. Agricultural Systems $\mathbf{5 5}$ (2):173-193.

9. Ingles, A.W., Mush, A., Qwist-Hoffman, H., 1999. The Participatory Process For Supporting Collaborative Management of Natural Ressource, FAO, Rome.

10. Krueger, R.A., Casey, M.A., 2000. Focus groups: a practical guide for applied reserach. (3rd Edition) Sage Publication - International Educational and Professional Publisher; London.

11. Loubier, S., Rinaudo, J.-D., 2004. Socio-cultural detreminants of water utilisation: Hérault river basin case study (France). Report BRGM/RP-53090-FR, Orléans, France:88. http://www.aquadapt.net

12. Mostert, E., 2003. The chalenge of public participation. Water Policy 5 (2):179-197.

13. Rinaudo J-D and Garin $P$ (in press) The benefits of combining lay and expert input for water management planning at the watershed level. Water Policy.

14. Theys, J., 2003. La gouvernance, entre innovation et impuissance : le cas de l'environnement. Revue Développement Durable et Territoires. Dossier 2 "Gouvernance locale et Développement durable" - novembre 2003 (http://www.revue-ddt.org) 